\title{
Dual Oxygen Therapy in Patient on Bilevel Positive Airway Pressure Prevented Invasive Mechanical Ventilation
}

\author{
Amarjeet Kumar, Lalit Kumar', Chandni Sinha, Neeraj Kumar, Umesh Kumar Bhadani \\ Department of Anaesthesia, All India Institute of Medical Sciences, 'Department of Pharmacology, Indira Gandhi Institute of Medical Sciences, \\ Patna, Bihar, India
}

\section{Abstract}

During noninvasive bilevel positive airway pressure (BiPAP) ventilation it is found that several times patients are unable to maintain oxygen saturation and develop breathing difficulty despite its high setting and high oxygen flow, further management requires invasive positive pressure mechanical ventilation. Increasing oxygen concentration inside the BiPAP mask using nasal cannula with addition of another flow meter not only increase oxygen saturation but also make the patient more comfortable and prevent intubation and its complications. This dual oxygen therapy is particularly useful in patients where non invasive ventilation is required and avoiding the need invasive mechanical ventilation. High-flow nasal cannula oxygen therapy has many advantages over traditional oxygen delivery systems. Here, we are going to report two cases of patients on BiPAP in which invasive positive pressure ventilation was prevented using dual oxygen therapy using nasal cannula with flow meter and BiPAP mask with addition another flow meter in a single sitting.

Keywords: Bi-level positive airway pressure, dual oxygen therapy, high-flow nasal cannula

\section{INTRODUCTION}

During noninvasive bilevel positive airway pressure (BiPAP) ventilation, it is found that several times patients are unable to maintain oxygen saturation and develop breathing difficulty despite its high setting and high oxygen flow. Increasing oxygen concentration inside the BiPAP mask using nasal cannula with addition another flow meter not only increase oxygen saturation but also make the patient more comfortable and prevent intubation and its complications. This dual oxygen therapy particularly is useful in patients where non invasive ventilation is required and avoiding the need invasive mechanical ventilation. The use of high-flow nasal cannula (HFNC) in treating adult critical illness patients is increasing, and it is now being used in many patients with addition of a range of different disease conditions.

Here, we are going to report two cases of patients on BiPAP in which invasive positive pressure ventilation was prevented using dual oxygen therapy using nasal cannula with flow meter and BiPAP mask with addition of another flow meter in single setting.

\begin{tabular}{|l|l|}
\hline \multicolumn{2}{|c|}{ Access this article online } \\
\hline Quick Response Code: & Website: \\
\hline & www.ijccm.org \\
\cline { 2 - 2 } & \\
\hline
\end{tabular}

\section{Case Reports}

Case 1

A 55-year-old patient with known case of bronchiectasis with respiratory distress, the high-resolution computed tomography finding show bronchiectatic changes in both lungs and minimal reticular thickening in the left lung [Figure 1]. ABG analysis on 15 lit of oxygen $\mathrm{pH} 7.22, \mathrm{PCO}_{2} 86, \mathrm{PO}_{2} 69, \mathrm{Na}^{+} 130$, $\mathrm{K}^{+} 3.4, \mathrm{HCO}_{3} 34, \mathrm{SPO}_{2} 90 \%$, BE 6.3. We gave BiPAP (A-40, Respironics) ventilation with inspiratory airway pressure/ expiratory airway pressure (IPAP/EPAP) - 12/6 (mm Hg) and $15 \mathrm{~L} / \mathrm{min}_{2}$ flow by oxygen flow meter (which generated $\mathrm{O}_{2}$ pressure at patient end of oxygen tube $=200 \mathrm{mmHg}$ as measured by sphygmomanometer, pressure gradient was $200-12=188 \mathrm{mmHg}$ ). Patient c/o apprehension, perspiration, desaturation $\left(\mathrm{SPO}_{2}\right.$ around $\left.75 \%\right)$. We gave oxygen through nasal cannula by another flow meter with extra oxygen flow

\section{Address for correspondence: Dr. Amarjeet Kumar, Department of Anaesthesia, All India Institute of Medical Sciences, Patna, Bihar, India. E-mail: amarjeetdmch@gmail.com}

This is an open access article distributed under the terms of the Creative Commons Attribution-NonCommercial-ShareAlike 3.0 License, which allows others to remix, tweak, and build upon the work non-commercially, as long as the author is credited and the new creations are licensed under the identical terms.

For reprints contact: reprints@medknow.com

How to cite this article: Kumar A, Kumar L, Sinha C, Kumar N, Bhadani UK. Dual oxygen therapy in patient on bilevel positive airway pressure prevented invasive mechanical ventilation. Indian J Crit Care Med 2017;21:604-6. 
of $10 \mathrm{~L} / \mathrm{min}$ and other supportive treatment such as standard antibiotics and intravenous frusemide $20 \mathrm{mg}$. After that, the patient became comfortable, $\mathrm{SPO}_{2} 98 \%$. The patient improved with time and arterial blood gas (ABG) after $4 \mathrm{~h}$ was within normal limit and patient recovered successfully.

\section{Case 2}

A 12-year-old female a case of chronic kidney disease on maintenance dialysis came to Intensive Care Unit with respiratory distress, chest examination showed crepts +++ . ABG on $15 \mathrm{~L} \mathrm{O}_{2}$ mask showed severe metabolic acidosis with $\mathrm{pH} 7.09, \mathrm{PO}_{2} 55, \mathrm{PCO}_{2} 40, \mathrm{SPO}_{2} 80, \mathrm{BE}-16$. We gave BiPAP (A-40, Respironics) ventilation with IPAP/EPAP-14/7 $\left(\mathrm{mm} \mathrm{Hg}\right.$ ) and $\mathrm{O}_{2}$ flow $10 \mathrm{~L} / \mathrm{min}$ (which generated $\mathrm{O}_{2}$ pressure at patient end of oxygen tube $=85 \mathrm{mmHg}$ as measured by sphygmomanometer and pressure gradient of $85-14=71 \mathrm{mmHg}$ ). There was increased respiratory distress and $\mathrm{SPO}_{2}$ fell to $70 \%$. We gave extra oxygen by nasal cannula with $\mathrm{O}_{2}$ flow 10 lit by another flow meter [Figure 2]. The patient became more comfortable, and $\mathrm{SPO}_{2}$ increased to 95\%. ABG showed PO2 $180 \mathrm{mmHg}, \mathrm{PCO}_{2} 35$, and SPO2 97\%. The patient recovered successfully from respiratory distress and thus invasive positive pressure ventilation was avoided.

\section{Discussion}

HFNC oxygen therapy has many advantages over traditional oxygen delivery systems, including decreased nasopharyngeal resistance, decrease in nasopharyngeal dead space, ${ }^{[1,2]}$ generation of positive pressure in the pharynx,,$^{[1,3,4]}$ increasing alveolar recruitment in the lungs, humidification of the airways, increased fraction of inspired oxygen, improvement in functional residual capacity, ${ }^{[1,5]}$ and better mucociliary clearance.

One study demonstrated that there is some degree of continuous positive airway pressure produced by HFNC therapy, which is both flow dependent and mouth position dependent. ${ }^{[4,6]}$ This effect was confirmed by studying the correlation between flow rate and pressure within the context of the Optiflow ${ }^{\mathrm{TM}}$ nasal

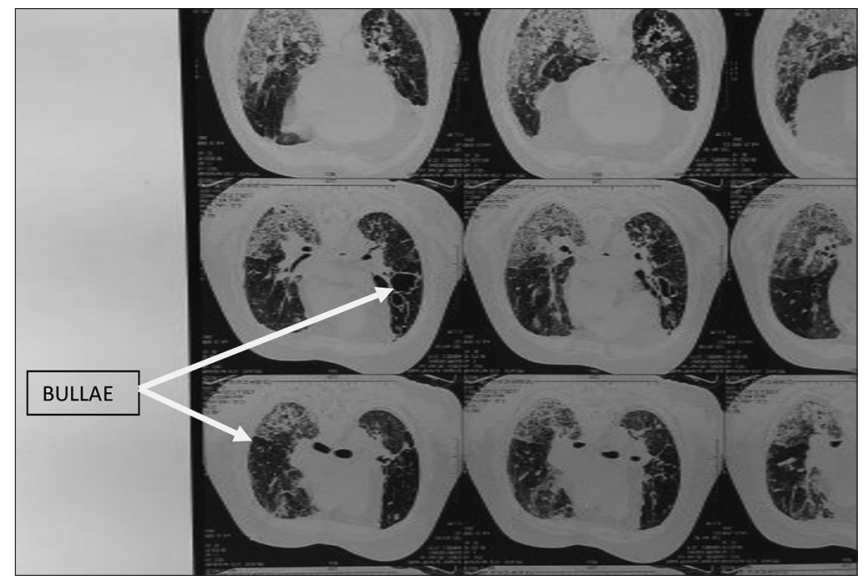

Figure 1: Case 1 - High-resolution computed tomography of the patient showing bronchiectatic changes high-flow oxygen therapy system. ${ }^{[5]}$ High-flow nasal cannula oxygen therapy has been proven to be a better alternative to conventional oxygen therapy for critically ill patients. Patients with respiratory failure, Pneumonia, and obstructive airways disease, either during the postextubation period or preintubation may get benefit by this method. The positive end-expiratory pressure is hard to measure in these settings, despite these uncertainties, recent studies indicate that HFNC oxygen therapy has beneficial effects for the early treatment of critically ill adult patients.

One study showed that noninvasive mechanical ventilation is feasible as a long-term home treatment in patients with diffuse bronchiectasis..$^{[5,7]}$

HFNC could be used to improve oxygenation in critically ill patients. $^{[8]}$

Nasal high-flow oxygen therapy system proved effective in patient with chronic obstructive pulmonary disease, dementia, and sleep-related hypoventilation. ${ }^{[8,9]}$

The reason behind desaturation on BiPAP may be due to a decrease of oxygen inflow into mask due to high pressure inside mask during positive pressure which results in a decrease in oxygen concentration inside the mask. The flow of oxygen through oxygen flow meter generated pressure at patient end in Case 1 was $200 \mathrm{mmHg}$, and in Case 2 it was $85 \mathrm{mmHg}$ as measured by sphygmomanometer by connecting the oxygen tube to sphygmomanometer. BiPAP machine generated pressure during inspiratory phase inside the mask (in Case $1=12 \mathrm{mmHg}$ and in Case $2=14 \mathrm{mmHg}$ and pressure gradient of 188 and $71 \mathrm{mmHg}$, respectively). This positive pressure hampered oxygen entry into the BiPAP mask. BiPAP allow oxygen entry during expiratory phase during which pressure inside mask is low. However, in Dual oxygen therapy in above two patients, oxygen concentration inside mask was maintained both during inspiratory and expiratory phase using extra oxygen by nasal cannula resulting in increased oxygen concentration inside the mask and

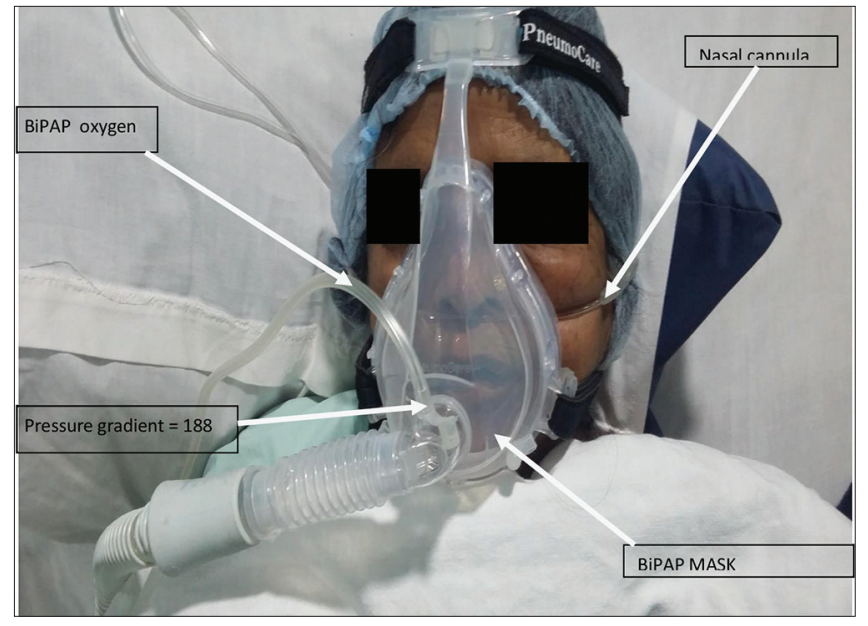

Figure 2: Case 2 - Patient on noninvasive ventilation, showing additional oxygen supply through nasal cannula 
hence preventing the patient from desaturation and avoiding endotracheal intubation. Overall mechanical ventilation was prevented, and hence, its associated complications were averted. There are various devices for increasing oxygen saturation such as high flow mask, venturi mask, but in this dual oxygen therapy, we provided high oxygen concentration with positive pressure, and prevented the use of ventilator and its complication.

\section{ConcLusion}

Dual oxygen therapy Increases oxygen concentration inside the BiPAP mask using nasal cannula with another flow meter and it not only increase oxygen saturation, but also make patient more comfortable and prevent intubation and its complications such as chance of bulla rupture in case of bronchiectasis, pneumothorax, ventilator associated pneumonia, failure of weaning from ventilation, as well as decrease hospital stay and cost.

The authors thus suggest the use of this technique of dual oxygen therapy in such cases where invasive mechanical ventilation is not desired or is contraindicated.

\section{Declaration of patient consent}

The authors certify that they have obtained all appropriate patient consent forms. In the form the patient(s) has/have given his/her/their consent for his/her/their images and other clinical information to be reported in the journal. The patients understand that their names and initials will not be published and due efforts will be made to conceal their identity, but anonymity cannot be guaranteed.

\section{Financial support and sponsorship}

Nil.

\section{Conflicts of interest}

There are no conflicts of interest.

\section{ReFERENCES}

1. Parke R, McGuinness S, Eccleston M. Nasal high-flow therapy delivers low level positive airway pressure. Br J Anaesth 2009;103:886-90.

2. Sztrymf B, Messika J, Bertrand F, Hurel D, Leon R, Dreyfuss D, et al. Beneficial effects of humidified high flow nasal oxygen in critical care patients: A prospective pilot study. Intensive Care Med 2011;37:1780-6.

3. Groves N, Tobin A. High flow nasal oxygen generates positive airway pressure in adult volunteers. Aust Crit Care 2007;20:126-31.

4. Riera J, Pérez P, Cortés J, Roca O, Masclans JR, Rello J. Effect of high-flow nasal cannula and body position on end-expiratory lung volume: A cohort study using electrical impedance tomography. Respir Care 2013;58:589-96.

5. Dewan NA, Bell CW. Effect of low flow and high flow oxygen delivery on exercise tolerance and sensation of dyspnea. A study comparing the transtracheal catheter and nasal prongs. Chest 1994;105:1061-5.

6. Okuda M, Kashio M, Tanaka N, Matsumoto T, Ishihara S, Nozoe T, et al. Nasal high-flow oxygen therapy system for improving sleep-related hypoventilation in chronic obstructive pulmonary disease: A case report. J Med Case Rep 2014;8:341.

7. Benhamou D, Muir JF, Raspaud C, Cuvelier A, Girault C, Portier F, et al. Long-term efficiency of home nasal mask ventilation in patients with diffuse bronchiectasis and severe chronic respiratory failure: A case-control study. Chest 1997;112:1259-66.

8. Gotera C, Díaz Lobato S, Pinto T, Winck JC. Clinical evidence on high flow oxygen therapy and active humidification in adults. Rev Port Pneumol 2013;19:217-27.

9. Parke RL, Eccleston ML, McGuinness SP. The effects of flow on airway pressure during nasal high-flow oxygen therapy. Respir Care 2011;56:1151-5 